\title{
Germán Montoya Sánchez
}

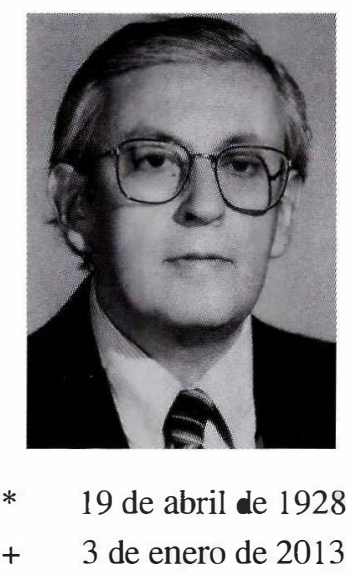

Qué responsabilidad tan enorme es escribir sobre aspectos de la vida y obra de una persona que por cosas del destino hoy ha dejado de acompañarnos en este mundo terrenal. Pero más que una responsabilidad constituye un verdadero reto y considero un inmerecido privilegio tener la oportunidad de expresar en estas cortas palabras la semblanza o el panegírico de un hombre que representó tanto para el proyecto institucional de la Sociedad de Cirugía de Bogotá-Hospital de San José y su Departamento de Ginecología y Obstetricia. Tuvo una gran influencia en la formación de cientos de profesionales de la ginecología y obstetricia de la escuela del Hospital de San José y en colegas de la especialidad a lo largo y ancho de la geografía de nuestro país.

El Profesor Germán Montoya Sánchez nació el 19 de abril de 1.928 en la hacienda Santa Bárbara (Usaquén, Cundinamarca) en el seno de una familia que por generaciones se había dedicado a la ganadería y a las faenas del campo. Estudió en el Gimnasio Moderno graduándose de bachiller en 1945, luego ingresó a la Pontificia Universidad Javeriana obteniendo el título de doctor en medicina y cirugía y después en 1956 se especializó en ginecología y obstetricia.

A la edad de 23 años conoce a su gran amor, Ligia Mejía Díaz-Granados, contrayendo con ella matrimonio en 1957 y con quien estuvo casado durante 55 años. De esta unión nacen tres hijos Juan Manuel, Francisco y Alejandro quienes aportaron a la familia tres nietos Pedro, Juan Pablo y Antonio. Siempre fue para él la familia su principal activo y en ella promovió el amor, la tolerancia y el respeto entre sus hijos, nueras y nietos. Amante y fiel defensor de su profesión y de la investidura que debería portar el médico dedicó su ejercicio a sus grandes pasiones como fueron el servicio al necesitado y a la Sociedad de Cirugía de Bogotá-Hospital de San José.

Pausada y discretamente como fueron todos los actos que rodearon su vida personal y profesional, porque así fue su último deseo, sin pompas ni honores se nos va el maestro, el esposo y padre de familia ejemplar, el colega, el amigo incondicional, pero sobre todo ese consejero siempre dispuesto, certero en sus juicios y franco en sus palabras, jamás se le conoció una actitud intransigente, imposición o arbitrariedad, tampoco muchos disgustos a pesar de la responsabilidad de dirigir el Departamento de Ginecología y Obstetricia de nuestro Hospital entre los años de 1983 y 1989, viviendo todo tipo de dificultades por las que durante este derrotero histórico se han vivido en nuestra querida institución hospitalaria.

Con gallardía, pero sobretodo fiel a sus principios y valores Gimnasianos que sin duda alguna nos inculcó a todos sus discípulos, a sus hijos Juan Manuel y Alejandro colegas de especialidad formados a su imagen y semejanza en esta casa del saber; también asumió el reto y la responsabilidad de dirigir y organizar la 
prestación de los servicios asistenciales y académicos del Departamento de Ginecología y Obstetricia de nuestro Hospital de San José, como la de formar durante muchos años, estudiantes de pre y posgrado de la Facultad de Medicina del Colegio Mayor de Nuestra Señora del Rosario, alcanzando la categoría de Profesor Titular, Profesor Honorario y jefe de la cátedra de la especialidad.

El Profesor Germán Montoya o el "Toche Montoya" como lo llamaban algunos de sus más queridos amigos y colegas, seguramente por apodo o sobrenombre heredado de la cultura y usanza en el Gimnasio Moderno de Bogotá, al que siempre se refirió con cariño y admiración, tanto que sus tres hijos Juan Manuel, Francisco y Alejandro también fueron educados y recibieron allí su grado de bachilleres de esta institución educativa que fundara e inspirara Don Agustín Nieto Caballero de grata recordación y una de las figuras más destacadas en la historia de la pedagogía Colombiana.

Tuve la fortuna de ser su alumno de pre y posgrado, su colega y su amigo, podría decir que fue como un padre y guía para mí y para muchos de nosotros; fue suave y bondadoso en muchas ocasiones de nuestras vidas, pero fue enérgico y fuerte cuando estaba en juego o se trataba de un principio, amigo fiel y leal consejero, siempre tuvo tiempo para oír y entregó su vida sin egoísmo alguno al servicio de los demás, ejerció dignamente y con amor su profesión como ginecólogo y obstetra, recibiendo el reconocimiento y cariño de sus pacientes, colegas y de todas las sociedades científicas a las que perteneció y de las cuales fue miembro activo y trabajador comprometido. Autor de un sinnúmero de artículos y capítulos de textos de la especialidad, nuestro querido profesor Montoya Sánchez ocupó cargos directivos en la Sociedad de Cirugía de Bogotá-Hospital de San José, de la cual fue también miembro Asociado desde 1971, de Número desde el año 1978 y Honorario hasta el momento de su fallecimiento. Siempre acudió con cariño, dedicación y cumplimento a nuestras reuniones mensuales y asambleas de la Sociedad de Cirugía de Bogotá y sólo por quebrantos de salud o de fuerza mayor dejó de acompañarnos con sus sabios consejos y comentarios bondadosos y atinados, que siempre recibí en el despacho de la Presidencia en animadas charlas particulares, minutos y horas antes de nuestras tradicionales reuniones, con el cariño y amistad que siempre me brindó durante todos estos doce años que he ocupado la presidencia de nuestra Sociedad, del Consejo Superior de la Fundación Universitaria de Ciencias de la Salud y de las juntas directivas de nuestros dos Hospitales, entre otras cosas gracias a su confianza, generosidad, lealtad y amistad incondicional.

A la señora Ligia Mejía de Montoya compañera inseparable y a sus hijos Juan Manuel, Francisco y Alejandro en compañía de sus esposas, hijos y demás familiares y amigos, queremos expresarles nuestro sentimiento de pesar y sentidas condolencias por la pérdida de este ser querido, esposo, padre y abuelo ejemplar. Para toda la comunidad del grupo empresarial de San José y en particular para el Departamento de Ginecología y Obstetricia de nuestro hospital, fue un modelo a seguir como maestro, mentor y colega; un hombre que recibió el premio del sembrador, vio la cosecha y recibió el fruto de sus desvelos. Su infatigable y larga tarea como formador de profesionales médicos, ginecólogos y obstetras deja un legado de varias generaciones de valiosos servidores en nuestro país y el exterior que lo hace merecedor de los más caros sentimientos de gratitud y aprecio.

Su recuerdo siempre acompañará a los que tuvimos el privilegio de conocerlo y compartir con él. Sabe que seguiremos fieles a sus enseñanzas, que lucharemos por los mismos ideales y su espíritu seguirá vivo entre nosotros. Recordemos a don Agustín Nieto: "He pensado que el atardecer de nuestroespíritu, mientras seamos centinelas de esta obra, será como uno de esos atardeceres llenos de un fuego que se obstina en no morir" 